\title{
Proteolytic mechanisms of cartilage breakdown: a target for arthritis therapy?
}

\author{
D J Buttle, H Bramwell, A P Hollander
}

Erosion of cartilage is a major feature of both osteoarthritis and rheumatoid arthritis which leads, with time, to loss of joint function. There are no existing approaches to therapy which will prevent this tissue destruction and a good understanding of the biochemical processes which cause it is therefore essential so that new targets for pharmacological intervention can be identified. The clinical rheumatologist observes loss of cartilage as joint-space narrowing on $x$ ray film. Biochemists can show that cartilage has been damaged more directly, by studying the tissue taken at joint replacement surgery in comparison with normal (control) cartilage. The simplest biochemical evidence for cartilage degradation is a demonstration of lower amounts of cartilage matrix proteins in arthritic tissue, indeed a reduction in the amount of total cartilage. In this respect, most attention has been paid to the two major proteins of cartilage, aggrecan, the large, aggregating proteoglycan, and type II collagen, both of which are present at reduced concentrations in arthritic tissue. ${ }^{1-3}$ More sophisticated approaches can be used to show that in arthritis a proportion of these two cartilage proteins are present in a degraded form. ${ }^{24-6}$ Kempson $^{7}$ has shown very clearly that selective degradation of proteoglycan from cartilage results in loss of compressive resistance of the tissue whilst selective degradation of collagen leads to loss of tensile strength. Thus, the two proteins serve different and complementary roles in cartilage and degradation of either molecule will result in profound changes in cartilage function. Whilst it is possible that some of the damage to protein structure in arthritis could be caused by free radicals, produced for example by neutrophils, it is more likely that the proteins have been subjected to proteolytic cleavage by specific enzymes (proteinases). The proteinases can be synthesised by chondrocytes under appropriate stimulation, or they could be produced by cells which have infiltrated the inflamed synovium (in rheumatoid arthritis). It is most likely that a series of proteinases act together in a cascade of proteolytic activation, resulting finally in protein degradation (see later). A detailed understanding of each stage in the cascade(s) will enable us to identify a variety of targets for pharmacological intervention in the arthritic process.

Proteolytic enzymes (peptide bond hydrolases, peptidases, proteases) are classified into four distinct types depending on their catalytic mechanism (serine, cysteine, aspartic, and metallo-), and also in terms of whether they hydrolyse peptide bonds in the middle of a protein (proteinases or endopeptidases) or towards either of the two termini (exopeptidases). ${ }^{8}$ Members of all four catalytic groups of endopeptidases are capable of hydrolysing cartilage components in vitro (for review see ${ }^{9}$ ), and certain exopeptidases may also be involved. As it is highly unlikely that all of these enzymes play a role in vivo, it is not possible to make any firm judgement about which enzymes are responsible for the physiological or pathological breakdown of cartilage components by extrapolating from experiments conducted in the test tube.

The majority of proteolytic enzymes are synthesised as inactive zymogens, or proproteins, and in most cases the activation of these enzymes is achieved by proteolytic cleavage of the precursor. Thus, the activity of one proteinase can be dependent on the activity of another, and an enzyme catalysing one ratelimiting step in cartilage breakdown may not itself be involved in digesting cartilage proteins. The situation can be further compounded by changes in the balance between the amounts of proteinases and their endogenous protein inhibitors.

Faced with dilemmas such as these, perhaps one of the best experimental approaches is to attempt to identify a functional link between the activity of a certain enzyme and the degree of cartilage breakdown in some kind of model system. This requires reagents that either react specifically with one or a few proteolytic enzymes and modulate their activity, or interfere with gene expression. Such methods may include the use of specific proteinase inhibitors, antisense oligonucleotides or RNAs, or gene disruption experiments. One might expect that recent advances in antisense and gene disruption techniques will soon result in their application to the question of which proteases are involved in cartilage breakdown. To date, 
however, only experiments using proteinase inhibitors have thrown any light on this subject.

\section{Models of cartilage breakdown}

Much of the work attempting to clarify the nature of the proteolytic enzymes involved in cartilage matrix breakdown has used tissue culture models. The simplest system is cartilage explants maintained in culture in the presence of a non-toxic reagent that induces matrix loss. By use of such models it became apparent that the resident cells of cartilage, the chondrocytes, were capable of causing the breakdown of their matrix; no involvement of other cell types, such as inflammatory cells or those of the pannus in rheumatoid arthritis, was necessarily required as the source of proteolytic activity.

The first explant culture system to be developed was reported by Fell and Mellanby in 1952. ${ }^{10}$ Micromolar concentrations of retinoids caused loss of proteoglycan from embryonic and fetal cartilaginous limb bud rudiments. The mechanism of action was unknown, and remains so despite a great deal of work over the past 40 years. It became clear that chondrocytes within the explants contained sufficient quantities of lysosomal proteinases to effect the breakdown of proteoglycan if these normally intracellular enzymes came into contact with the extracellular matrix components. ${ }^{11-13}$ One way by which the lipophilic retinoids could obviate this is by destabilisation of the lysosomal and plasma membranes, and in fact there is some evidence to support this mechanism. ${ }^{12}$ Of particular interest was the recent report that $10 \mu \mathrm{M}$ retinoic acid disrupted the Golgi apparatus and altered protein trafficking in certain transformed cell lines by a receptor independent mechanism. ${ }^{14}$ Alterations in endocytosis and/or secretion of proteins, and in targeting of lysosomal enzymes could provide a mechanism by which normally intracellular proteinases gain access to extracellular matrix components. Although the concentration of the vitamin required to produce rapid loss of aggrecan from cartilage explants is well above the dissociation constant of most of the nuclear retinoid receptors, the retinoid $\mathrm{X}$ receptors are activated by all-trans-retinoic acid only at ligand concentrations of $10^{-6} \mathrm{M}$ or more. ${ }^{15} \mathrm{It}$ is possible therefore that the effect of retinoids on aggrecan breakdown is a receptor mediated process.

The realisation that the proinflammatory cytokines interleukin-1 (IL-1) and tumour necrosis factor- $\alpha$ (TNF $\alpha$ ) also stimulate cartilage proteoglycan breakdown ${ }^{1617}$ incited much activity in the field, particularly when it was realised that these cytokines are usually found in the joint in arthritis ${ }^{1819}$ and IL-1 can cause aggrecan release when injected into the joints of live animals. ${ }^{20}$ IL-1 and TNF $\alpha$ cause rapid loss of aggrecan from cartilage explants at nanomolar concentrations and there is little doubt that they are acting via their respective signalling pathways.

There are certain other reagents that appear to cause increased breakdown and loss of aggrecan from cartilage explants, such as extracellular ATP ${ }^{21}$ and fibronectin fragments. ${ }^{22}$

\section{Proteinases implicated in the breakdown} of aggrecan

THE INVOLVEMENT OF A CYSTEINE PROTEINASE: CATHEPSIN B

The mammalian cysteine proteinases consist of the lysosomal enzymes cathepsins B (EC 3.4.22.1), L (EC 3.4.22.15), H (EC 3.4.22.16), and $S$ (EC 3.4.22.27), and the cytosolic calcium requiring enzyme calpain (EC 3.4.22.17). A cysteine proteinase was the first enzyme to be suspected of involvement in cartilage proteoglycan breakdown, because of the results reported by Thomas as long ago as $1956 .^{23}$ Reversibly oxidised papain (EC 3.4.22.2), a plant cysteine proteinase evolutionarily related to the mammalian lysosomal cysteine proteinases, ${ }^{24}$ was capable of digesting cartilage proteoglycans when injected intravenously into rabbits. Cysteine proteinase activity depends on the sulfur atom of the active site cysteine residue of the enzyme being in a reduced state. This pioneering work thus demonstrated the ability of cartilage to activate an oxidised form of the enzyme, and also the capacity of the enzyme to act on cartilage proteoglycans in vivo. It was later demonstrated that the autolytic breakdown of killed cartilage was accelerated by the addition of cysteine and inhibited by the thiol blocking reagents iodoacetamide and mercuric chloride, ${ }^{25}$ suggesting the presence of a cysteine proteinase (such as cathepsin B) within chondrocytes that has the capacity to degrade proteoglycan. ${ }^{26}$

For the next 20 years, very little work on the involvement of cathepsin B in aggrecan breakdown was reported. However, in 1987 van Noorden et $a l^{7}$ detected, using enzyme histochemistry, cathepsin B activity in freshly prepared neonatal mouse cartilage chondrocytes. Although enzyme activities were lower than those in the nearby perichondrial fibroblasts, this was perhaps the first clear demonstration of the presence of cathepsin B activity within chondrocytes. The question of whether the amount of enzyme might be influenced by agents that lead to aggrecan breakdown was addressed by Baici and Lang. ${ }^{28}$ They reported an increase in chondrocyte cathepsin $B$ activity following stimulation of the cells in monolayer culture with IL-1 $\beta$. It was not clear, however, whether this increase in activity was a property of fully differentiated cells as they had to be passaged in order to demonstrate this response, and chondrocytes are known to change their phenotype following such treatment. $^{29}$

The first direct evidence to suggest that cysteine proteinases may actually be playing a role in the development of an arthritis came with the use of a selective inactivator of these enzymes in an animal model of the disease. Benzyloxycarbonyl-Phe-Ala $\mathrm{CH}_{2} \mathrm{~F}$ was administered either intravenously, orally or directly into the affected knee joint of rats with adjuvant induced arthritis. In control samples the cathepsin B 
activity (measured histochemically) of synoviocytes, chondrocytes and fibroblasts within the joint increased during antigen induced arthritis. The administration of the peptidyl fluoromethane caused a reduction in cathepsin B activity, inflammation and cartilage damage. ${ }^{30}$ This compound is an irreversible inactivator of the cysteine proteinases in general, and in fact inactivates cathepsins $S$ and $L$ faster than cathepsin $\mathrm{B} .^{31}$ This raises the question of which cysteine proteinase(s) might be involved in the development of antigen induced arthritis. Other questions also arose from this work. For instance, was the inhibition of cartilage erosion a direct effect of the inhibition of a cysteine proteinase or was it secondary to the reduction in inflammation? Was the reduction in damage to cartilage in the presence of the inactivator due to inhibition of proteoglycan or collagen breakdown, or both?

The use of cysteine proteinase inactivators in cartilage culture systems has gone some way to answering these questions. The application of CA074, an inactivator highly specific for cathepsin $\mathrm{B},{ }^{32}$ has demonstrated that it is this cysteine proteinase that is involved in chondrocyte mediated IL-1 stimulated proteoglycan loss from cartilage. However, it appears unlikely that cathepsin B is having a direct catabolic effect on aggrecan, as only lipophilic inactivators are effective, ${ }^{33} 34$ suggesting an intracellular role. In the case of CA074 the compound is perhaps two orders of magnitude more potent $\left(\mathrm{IC}_{50}<1 \mu \mathrm{M}\right)$ if administered as the lipophilic methyl ester, CA074Me, ${ }^{35}$ even though this is not a cathepsin B inactivator. ${ }^{32}$ The methyl ester is presumably converted to the active compound by intracellular esterases after entering the cell. The fact that an inhibitor of the vacuolar type $\mathrm{H}^{+}$-ATPase inhibits chondrocyte mediated proteoglycan degradation ${ }^{36}$ is independent evidence for a role for intracellular acidic compartments in aggrecan breakdown.

\section{THE INVOLVEMENT OF THE MATRIX}

\section{METALLOPROTEINASES}

Metalloproteinases normally utilise a zinc atom in the catalytic mechanism, and recent structural studies have shown this to be the case for the matrix metalloproteinases. ${ }^{378}$ This subfamily of proteinases has recently been found to exhibit some common structural features with metalloproteinases in the metzincin family $^{39}$ of the MA clan. ${ }^{24}$ The matrix metalloproteinases are a large and still growing group of enzymes that, along with many other mammalian proteinases, are capable of hydrolysing extracellular matrix components. ${ }^{40}$ What makes it appear quite likely that this is their prime function is the fact that they are synthesised by mesenchymal cells and either secreted directly into the matrix (as inactive proproteinases) or retained at the cell surface. The matrix metalloproteinases have been implicated in pathological connective tissue breakdown in diseases such as osteoporosis, periodontitis, tumour invasion, and metastasis. ${ }^{40}$ There are three major subgroups of matrix metalloproteinases: the collagenases, the gelatinases and the stromelysins, although at least two other subgroups may also exist. ${ }^{41}$

Proinflammatory cytokines have been shown to stimulate a variety of mesenchymal cells to produce and secrete increased amounts of matrix metalloproteinase precursors such as interstitial procollagenase (EC 3.4.24.7 $)^{42}$ and prostromelysin 1 (EC 3.4.24.17). ${ }^{43}$ This has led to the widely held view that matrix metalloproteinases are the enzymes primarily responsible for cartilage matrix breakdown, ${ }^{44}$ although until quite recently direct evidence for this viewpoint was hard to come by. Over the past few years, a number of papers have described the inhibition of cartilage explant proteoglycan breakdown by inhibitors of the matrix metalloproteinases, ${ }^{3545-47}$ with the most potent having an $\mathrm{IC}_{50}$ of about $0 \cdot 1 \mu \mathrm{M} .{ }^{35}$ In contrast to cathepsin B inhibitors, matrix metalloproteinase inhibitors are capable of suppressing retinoate stimulated as well as IL-1 stimulated cartilage proteoglycan breakdown. ${ }^{35}$

Which of the matrix metalloproteinases are involved in aggrecan breakdown is far from clear. The matrix metalloproteinase inhibitors found to be effective are broad spectrum compounds capable of inhibiting many of this subgroup of proteinases. More selective inhibitors are now becoming available for testing, and work in our laboratory suggests that stromelysin and gelatinase type enzymes are not involved (C J Brown, S Rahman, D J Buttle, manuscript in preparation). It is also not clear if the matrix metalloproteinases are acting directly on the aggrecan molecule or as activators of other enzymes in a cascade (see later).

\section{THE INVOLVEMENT OF PLASMINOGEN}

\section{ACTIVATORS AND PLASMIN}

Plasminogen activators catalyse cleavage of plasminogen to yield the serine proteinase plasmin (EC 3.4.21.7). Plasmin is capable of degrading all of the components of extracellular matrix, either directly ${ }^{48}$ or indirectly by activating the proforms of cartilage degrading enzymes. ${ }^{49}$ There are two types of plasminogen activator (for review see ${ }^{50}$ ) which differ in size and immunological reactivity and are encoded by separate genes. ${ }^{5152}$ The two enzymes, urokinase type plasminogen activator (u-plasminogen activator; EC 3.4.21.73) and tissue type plasminogen activator ( $t$-plasminogen activator; EC 3.4.21.68) catalyse the same cleavage within the plasmin molecule ${ }^{53}$ but are produced by different cell types and localised to distinct sites. The t-plasminogen activator is thought to be involved primarily in clot lysis. ${ }^{54}$ The pro- and active forms of u-plasminogen activator can be localised at the surface of cells by binding to specific receptors. ${ }^{556}$ Receptor binding serves the dual functions of localising the plasminogen activator activity at the cell surface and providing steric hindrance to inhibition by the protein inhibitors of u-plasminogen activator, and plasminogen activator inhibitors-1 and -2 (PAI-1 and PAI-2). Dingle and Dingle ${ }^{57}$ showed that proteoglycan added to cartilage could only be degraded if it could diffuse freely into the matrix, suggesting that 
the enzymes catalysing degradation are localised close to the chondrocytes.

The evidence that plasminogen activators are involved in cartilage degradation is mostly circumstantial. The activities of plasminogen activators are increased by the addition of IL- $1,{ }^{5859} \mathrm{TNF} \alpha$, TNF $\beta,{ }^{60}$ and retinoic acid $^{61}$ in chondrocytes. The latter study showed that retinoate stimulated plasminogen activator is located in the pericellular space and therefore exists at the probable site of proteoglycan degradation. ${ }^{5762}$ The association of plasminogen activator and PAI-1 complexes with some extracellular matrices ${ }^{6364}$ may provide a store of the enzyme for matrix turnover. IL- 1 induced proteoglycan degradation is enhanced by the addition of plasminogen. ${ }^{65}$ This suggests that IL-1 enhances plasminogen activator activity and, where plasminogen is present, this leads to an increase in plasmin concentration. Plasmin may then activate latent matrix metalloproteinases involved in cartilage breakdown.

As with cathepsin B and the matrix metalloproteinases, specific proteinase inhibitors are providing a functional link between enzyme activity and aggrecan breakdown. Work carried out in our laboratory (H Bryson, J C Powers, R A D Bunning, D J Buttle, manuscript in preparation) using the substituted isocoumarin ACITIC $^{66}$ has shown that this molecule is a rapid inactivator of $\mathrm{u}$-plasminogen activator, $\mathrm{t}$ plasminogen activator and plasmin, and suppresses the release of proteoglycan fragments from bovine cartilage cultures.

Several workers have addressed the question of whether the balance between plasminogen activator and PAI levels is altered in patients with arthritic disease. Increased activities of uplasminogen activator are seen in cells removed from osteoarthritis cartilage ${ }^{67}$ and PAI-1 concentrations are seen to be decreased at the same sites. Increases in plasminogen activator activity have also been seen in the synovial fluid of patients with rheumatoid arthritis. ${ }^{6869}$ However, other studies have shown that patients with severe disease tend to exhibit decreased fibrinolytic activity and that this may be linked to an increased concentration of PAI- 1 in the serum. ${ }^{70}$

EVIDENCE FOR THE INVOLVEMENT OF A NOVEL PROTEINASE, "AGGRECANASE"

The loss of proteoglycan from cartilage leads to a reduction in the hydration of the matrix and consequent reduction in compressive stiffness. The major proteoglycan of cartilage, aggrecan, is held within the matrix by a non-covalent association with hyaluronic acid, the interaction between the two macromolecules being stabilised by link protein. The aggrecan molecule consists of up to three globular regions and an extended glycosaminoglycan binding region which is itself subdivided into keratan sulfate rich and chondroitin sulfate rich domains. ${ }^{71}$ The loss of aggrecan from human cartilage occurs after a specific proteolytic cleavage within the interglobular domain between G1 and G2. Fragments of aggrecan purified from synovial fluid of normal and arthritic joints ${ }^{672}$ as well as from the media of cartilage explant cultures, either unstimulated or stimulated to induce cartilage degradation,,$^{353-75}$ all have the same $\mathrm{N}$ terminal sequences. Comparison of these sequences with that of intact aggrecan shows that the fragments are produced after proteolysis at one of three positions within the molecule in the case of bovine aggrecan. Just one cleavage site has been identified in human aggrecan breakdown. All the sites have a glutamic acid residue in the P1 position of the cleavage site and a small aliphatic residue in $P 1^{\prime}$ (in the accepted terminology ${ }^{8}$ ). The small number of cleavages and the similarity of amino acids found at the cleavage sites suggest that aggrecan breakdown is catalysed in vivo by a single glutamyl endopeptidase. To date, no known mammalian proteinase with specificity for cleavage after Glu has been identified and this fact has led to the hypothesis that a novel enzyme, which has been called "aggrecanase", is responsible for aggrecan degradation. However, the detection of a limited number of specific fragments does not preclude the possibility that other enzymes are involved in aggrecan degradation, as initial cleavage at the $\mathrm{N}$ terminal side of the known cleavage sites might precede cleavage after Glu, yielding small fragments which would be difficult to detect.

The evidence that matrix metalloproteinases are involved in aggrecan degradation has been described earlier. Several known enzymes belonging to this class cleave aggrecan at the Asn341-Phe 342 bond within the interglobular domain $^{7677}$ but none of these enzymes has the restricted specificity of "aggrecanase". There is evidence that this Asn-Phe bond is cleaved in some culture systems. ${ }^{78}$ Hence "aggrecanase" may not be the only enzyme directly involved in aggrecan degradation. However, the predominance of cleavages catalysed by "aggrecanase" in vivo and in vitro indicate that this activity is of major importance in aggrecan breakdown and represents a potentially important therapeutic target.

Neutrophil collagenase (EC 3.4.24.34) cleaves aggrecan at both the Asn-Phe and the Glu-Ala "aggrecanase" cleavage site within the interglobular domain of a tryptic fragment of aggrecan in vitro. ${ }^{79}$ The enzyme activities originally used to detect "aggrecanase" activity were very high but could be reduced by the addition of polyethylene glycol, which is presumed to mimic the viscosity of the extracellular matrix. However, the enzyme still cleaved at the Asn-Phe bond in preference to the Glu-Ala "aggrecanase" cleavage site. The authors failed to detect neutrophil collagenase messenger RNA (mRNA) in chondrocytes by the very sensitive reverse transcription polymerase chain reaction (PCR) method. It therefore appears very likely that neutrophil collagenase is not responsible for "aggrecanase" activity in cartilage explant cultures and in vivo.

\section{Link protein degradation}

The non-covalent binding between the aggrecan monomer and hyaluronate, important to the retention of aggrecan within the tissue, 
is stabilised by link protein. This protein is known to be slowly cleaved in vivo, resulting in the accumulation in older individuals of a new electrophoretic population of the molecule that contains three distinct proteolytically generated $\mathrm{N}$ termini. The cleavage of link protein at these positions does not alter its functional integrity, but it can be used as a marker for proteolytic activity occurring within cartilage. ${ }^{80}$ Stromelysin 1 is capable of generating one of the $\mathrm{N}$ termini in vitro, and both cathepsin $\mathrm{B}$ and the neutrophil serine proteinase cathepsin G (EC 3.4.21.20) can generate another. The $\mathrm{N}$ terminus consistent with the action of stromelysin 1 prevails in the neonate, providing evidence that proteolytic activity exists within cartilage throughout life, though the identity of the proteinases present may change somewhat. There is no evidence for any alteration in proteolytic modification of link protein associated with disease processes. ${ }^{80}$ Link protein is also cleaved at other positions, possibly compromising the interaction between link protein and aggrecan, but as yet no proteinase responsible for these cleavages has been identified. ${ }^{81}$

\section{Collagen degradation}

\section{COLLAGEN STRUCTURE}

Type II collagen is the predominant collagen type in cartilage and it endows this tissue with its tensile strength. ${ }^{7}$ Like other fibrillar collagens, it consists of three $\alpha$-chains wound into a triple helix and in the case of type II collagen the $\alpha$-chains are identical with each other and encoded by a single gene located on human chromosome $12 .^{82} \mathrm{By}$ convention the intact, fully wound helical molecule is called native collagen whilst the unwound $\alpha$-chains are called denatured collagen or gelatin. The native molecule is synthesised with large amino and carboxy terminal propeptides which are rapidly removed by specific proteinases in the extracellular matrix. ${ }^{83}$ The mature type II collagen molecule is incorporated into collagen fibrils. It contains short, non-helical telopeptides at its amino and carboxy termini, 18 and 27 amino acids in length, respectively. By comparison, the intervening triple helical region is 1014 amino acids long. The telopeptides are critical for the formation of stable collagen fibrils as they provide some of the covalent cross-links so important to the tensile strength of collagen fibrils. The entire helical region contains the repeating amino acid sequence Gly-X-Y, where the $\mathrm{X}$ position amino acid is often proline and the $\mathrm{Y}$ position residue is often hydroxyproline or hydroxylysine. The latter may act as sites for O-linked glycosylation and also for the formation of covalent cross-links. There are four potential cross-linking sites in type II collagen, one in each telopeptide and one towards each end of the triple helix. The number of these sites that are actually used in cross-links increases with age and this observation reflects the fact that there is very little turnover of the type II collagen in adult human articular cartilage.
EVIDENCE FOR TYPE II COLLAGEN DEGRADATION IN ARTHRITIS

Damage to the type II collagen fibrillar network was first observed in electron microscopic studies of articular cartilage from patients with rheumatoid arthritis. ${ }^{8485}$ Venn and Maroudas ${ }^{3}$ measured the hydroxyproline content of osteoarthritic and normal cartilage and thereby demonstrated a consistently lower level of cartilage collagen in osteoarthritis. More recently, Dodge et al developed an immunohistochemical method for the detection of unwound type II collagen $\alpha$-chains in situ in damaged cartilage. ${ }^{45}$ They raised a polyclonal antibody to peptides of type II collagen and demonstrated that the antiserum would only react with its epitope(s) in denatured type II collagen and not in the native molecule because the epitopes were normally hidden on the inside of the triple helix. They showed that immunohistochemical staining of denatured type II collagen was more extensive in cartilage from patients with osteoarthritis and rheumatoid arthritis than in control cartilage. Hollander et $a l^{2}$ extended this work by making a monoclonal antibody directed against a short synthetic peptide sequence representing a hidden epitope in the type II collagen molecule. The epitope could be selectively extracted from denatured and native type II collagen and its concentrations measured using an inhibition enzyme linked immunosorbent assay (ELISA). In this way it was demonstrated that there is a small but statistically significant increase in the amount of denatured type II collagen that can be extracted from either osteoarthritis or rheumatoid arthritis cartilage compared with control tissue. Taken together, all of these studies indicate that damage to type II collagen leading to its denaturation is a characteristic change that takes place in arthritis. All of the studies, however, focused on late stage disease, when cartilage samples could be obtained at joint replacement surgery and it is not yet known if collagen denaturation also occurs early on in the course of disease.

There are four ways in which proteinases could contribute to degradation of the type II collagen molecule. Firstly, cleavage of the native triple helix will lead to spontaneous denaturation of the molecule. The only mammalian proteinases known to be capable of type II collagen helical cleavage are the specific collagenases, interstitial collagenase and neutrophil collagenase, which hydrolyse a single Gly-Leu bond, three quarters of the way from the amino terminus of each $\alpha$-chain. ${ }^{8687}$ The cysteine proteinase cathepsin B is capable of cleaving the native triple helix of type I collagen, which is not a component of articular cartilage, at acid $\mathrm{pH}^{88}$ making an intracellular (phagocytic) pathway of collagen breakdown a possibility. However, there is no evidence that cathepsin B is capable of cleaving the type II collagen helix. Similarly, neutrophil elastase (EC 3.4.21.37) may be capable of cleaving the native triple helix of type I, but not type II, collagen. ${ }^{89}$

Secondly, cleavage in one or both telopeptides will remove cross-links and could 
depolymerise the collagen fibrillar network without actually damaging the helical structure of the type II collagen. Stromelysin 1 can cleave the amino terminal telopeptide of type II collagen at two distinct sites close to the start of the triple helix, so separating the telopeptide cross-link from the rest of the collagen molecule. ${ }^{90}$ Neutrophil elastase releases intact type II collagen $\alpha$-chains from articular cartilage, presumably by removal of cross-links from one or both telopeptides, ${ }^{89}$ although a specific cleavage site has not yet been identified. There are probably other proteinases capable of degrading the telopeptides, and it is important that these cleavages should be well characterised so that the role of this mechanism of damage to type II collagen in arthritis can be studied in detail.

Thirdly, cleavage of the unwound $\alpha$-chains in denatured type II collagen (gelatin) can be seen as a mechanism of clearance of damaged collagen from the extracellular matrix. Gelatinases A (EC 3.4.24.24) and B (EC 3.4.24.35) are particularly efficient at cleaving denatured collagen. ${ }^{40}$ Most proteolytic enzymes, however, have gelatinolytic activity and certain exopeptidases may be instrumental in the final stages of collagen breakdown. ${ }^{91}$ By definition, the collagen triple helix must already have been damaged, presumably by collagenase, before gelatinolytic activity can commence. Cleavage by collagenase is often regarded as the rate-limiting step in degradation of the triple helix although proteolytic activation of procollagenase is also likely to be a regulatory step. It is not clear if subsequent clearance of the unwound $\alpha$-chains is a necessary event, perhaps to facilitate any attempt by chondrocytes to repair their degraded matrix, or if it causes more damage to the cartilage through loosening of intermolecular interactions and thus enhanced loss of aggrecan from the matrix. Tissue culture experiments with specific inhibitors of gelatinolytic enzymes may help to resolve this question.

Fourthly, proteolytic activation of the proteinases directly mediating cleavage of the telopeptides, native helix or gelatin may be a very important mechanism for regulating collagen degradation. Indeed, as we postulate for aggrecan breakdown, there is probably a cascade of enzymes that may include cathepsin B, plasminogen activators, plasmin, neutrophil serine proteinases, and matrix metalloproteinases. For example, cathepsin B or plasmin may activate prostromelysin $1 .^{92}$ Active stromelysin may then cleave the telopeptides of type II collagen and also activate procollagenase,${ }^{93}$ leading to subsequent helix cleavage. From the point of view of pharmacological intervention, the activating enzymes might be a very good target for inhibition if they do in fact regulate a series of downstream, cascading events (see later).

WHICH PROTEINASES DEGRADE TYPE II COLLAGEN IN ARTHRITIS?

From the discussion above it is clear that in arthritis there is damage to the helical region of type II collagen and this is most likely the result of cleavage of the helix by collagenase. However, the role of collagenase remains putative and needs to be proven. It is not clear which, if any, of the other possible mechanisms of proteolytic damage outlined above contribute to collagen degradation in arthritis.

Tissue culture models of collagen degradation have only occasionally been used to study type II collagen breakdown, probably because it takes two to four weeks of culture with IL-1 before any significant collagen damage is observed. Ellis $\mathrm{et} \mathrm{al}{ }^{94}$ showed that collagen degradation in bovine nasal cartilage, as judged by release of hydroxyproline into the culture medium, could be inhibited by the protein inhibitor, tissue inhibitor of metalloproteinases (TIMP), and by a low molecular weight inhibitor of collagenase. Using the more specific assay for denatured type II collagen (see earlier), we have also found that a low molecular weight collagenase inhibitor can prevent collagen denaturation or release from cultured bovine nasal cartilage (A P Hollander, T Heathfield, A Reiner, A R Poole, manuscript in preparation). The use of other proteinase inhibitors with different specificities will allow us to dissect the proteolytic cascade which leads to collagen degradation in this model.

To determine which proteinases cleave type II collagen in human arthritic cartilage, proteinase specific cleavage sites in type II collagen must be determined in vitro and then identified in arthritic cartilage. For example, vertebrate collagenases cleave type II collagen at a single, specific Gly-Leu bond. The products of that cleavage, namely the $3 / 4$ and $1 / 4$ fragments, have never been isolated from arthritic cartilage, probably because they are cleaved to smaller fragments by gelatinolytic enzymes. The most fruitful method for detection of the collagenase cleavage site is likely to be the production of an antibody to the neoepitope amino terminal region of the $1 / 4$ fragment produced by collagenase cleavage. Hughes et a ${ }^{95}$ have shown that it is possible to generate such cleavage site specific antibodies. A similar approach can be taken for the known stromelysin cleavage sites in the telopeptide region of type II collagen ${ }^{90}$ to determine whether those cleavages have occurred in arthritic cartilage. Once the potential role of other proteinases in collagen cleavage has been established from tissue culture experiments using specific inhibitors, their cleavage sites in type II collagen can be determined in vitro and neoepitope antibodies generated for further analysis of arthritic cartilage.

It is likely that the approach outlined above will yield firmer evidence that collagenase cleavage is an important part of the collagen degradation process. It is less clear at this stage if telopeptide cleavages will be found to play any significant role in damage to the fibrillar network.

\section{The proteolytic cascades of cartilage}

Proteinase cascade reactions are known to be of importance in the body's response to crisis 


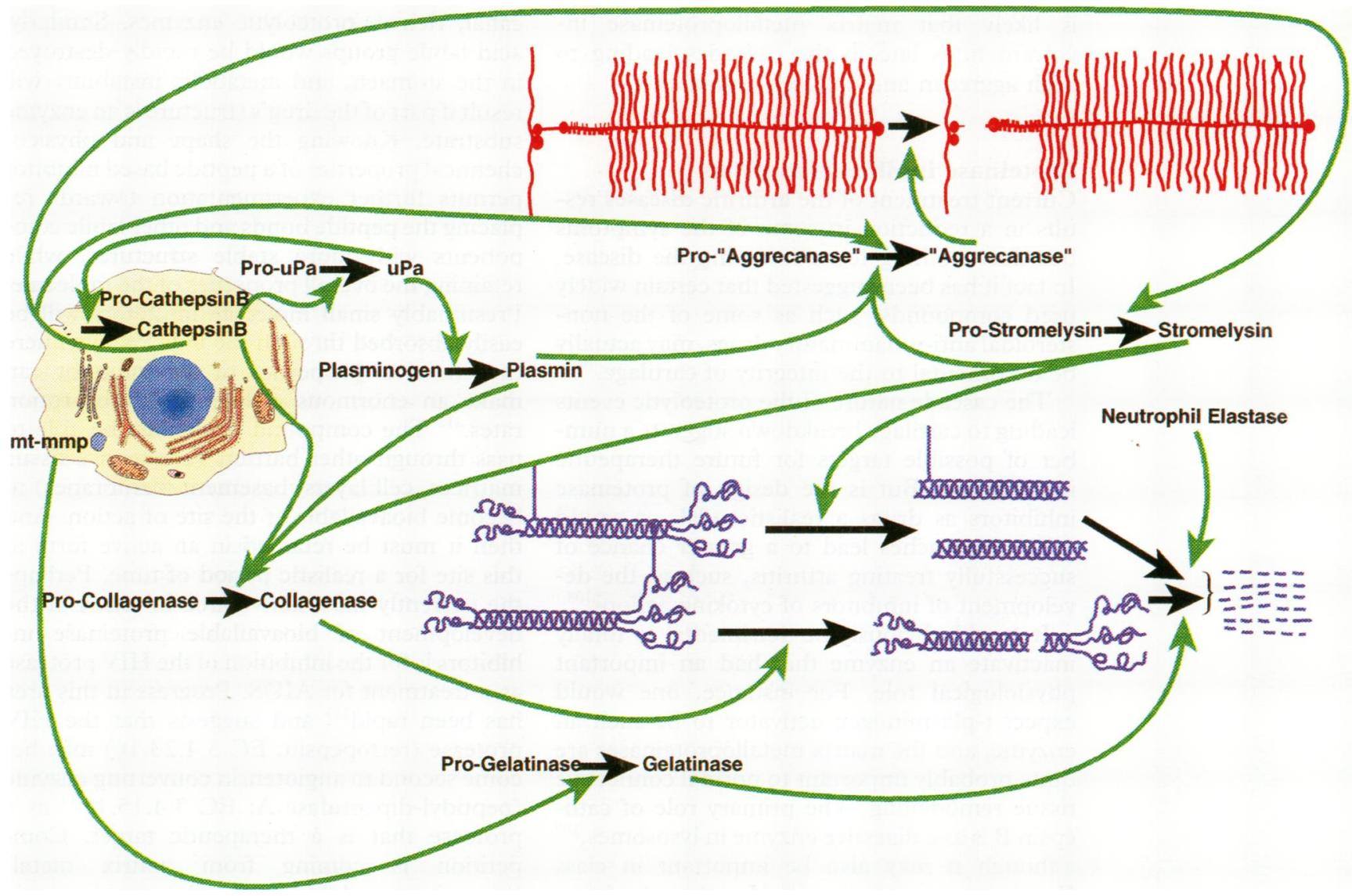

Putative proteinase cascades leading to cartilage aggrecan and type II collagen breakdown. The studies describing the evidence for the existence of the various pathways are cited in the text. The involvement of cathepsin $B$ is possibly intracellular and there is evidence for a pericellular role for $u$ plasminogen activator ( $u \mathrm{~Pa}$ ) and the "membrane-type" matrix metalloproteinase (mt-mmp). The involvement of other proteinases in the cascade is inferred from in vitro experiments using proteinase inhibitors and observation of the activating cleavages in the test tube. The exceptions are the activating mechanisms for the hypothetical enzyme "aggrecanase" for which there is currently no evidence. The ability of collagenase to cleave the helical region of type II collagen, stromelysin and other proteinases to cleave the non-helical regions, and gelatinases and other gelatinolytic enzymes to cleave denatured type II collagen is known from in vitro experiments. The action of "aggrecanase" on aggrecan is surmised. Link protein is also cleaved by various proteinases, but the cleavages so far identified do not lead to any functional impairment.

(the coagulation and complement cascades). The simplest way to interpret the data regarding aggrecan and collagen breakdown is to invoke a proteolytic cascade reaction (figure). In terms of aggrecan breakdown, the observation that almost complete inhibition can be achieved by inhibitors of at least three distinct proteinases is evidence that these enzymes are acting "in series" rather than "in parallel". Most of the evidence (with the exception of the differential effects of the cathepsin B inhibitor on IL-1 and retinoate stimulated aggrecan breakdown) would suggest that the same cascade is occurring in normal and pathological aggrecan breakdown. It seems likely that u-plasminogen activator and cathepsin B are acting early in the cascade reaction. Cathepsin B may well be acting intracellularly (although its action in an acidic pericellular compartment cannot be ruled out ${ }^{62}$ ). It is capable of activating prou-plasminogen activators, ${ }^{96}$ interstitial procollagenase $^{97}$ and prostromelysin $1^{92}$ in vitro, and may therefore also turn out to be important in the events leading to collagen breakdown. One property that makes cathepsin B a good candidate to be at the beginning of a cascade reaction is that it does not require the action of another proteinase for activation as it can autoactivate at the low $\mathrm{pH}$ found within the lysosome. ${ }^{98}$ As well as plasminogen, u-plasminogen activator can also activate procathepsin B. ${ }^{99}$ Plasmin is capable of activating the collagenase and stromelysin type matrix metalloproteinases and is considered to be one of the most important physiological activators of these enzymes. It is not an efficient activator of the gelatinases, however. ${ }^{40} \mathrm{~A}$ recently discovered membrane-bound matrix metalloproteinase ("mt-mmp") ${ }^{100}$ may be instrumental here.

The question arises as to whether "aggrecanase" is a matrix metalloproteinase. As discussed earlier, it is unlikely to be neutrophil collagenase. But matrix metalloproteinase inhibitors do inhibit aggrecan breakdown, and matrix metalloproteinases do not usually act as activating enzymes, other than of other matrix metalloproteinases (for example, the stromelysin 1 activation of interstitial procollagenase). ${ }^{93}$ Arguing against "aggrecanase" being a matrix metalloproteinase is the observation that matrix metalloproteinase synthesis is usually, ${ }^{101-104}$ but not always, ${ }^{105}$ downregulated by retinoids, which stimulate aggrecan breakdown. Also, the only proteinases so far described to have strict specificity for glutamyl bonds are not metalloproteinases but serine proteinases. ${ }^{106}$ Whether or not "ag- 
grecanase" is a matrix metalloproteinase, it is likely that matrix metalloproteinase involvement is late in the cascades leading to both aggrecan and collagen breakdown.

\section{Proteinase inhibitors as drugs}

Current treatment of the arthritic diseases results in a reduction in some of the symptoms but does nothing towards curing the disease. In fact it has been suggested that certain widely used compounds, such as some of the nonsteroidal anti-inflammatory drugs, may actually be detrimental to the integrity of cartilage. ${ }^{107}$

The cascade nature of the proteolytic events leading to cartilage breakdown suggests a number of possible targets for future therapeutic intervention. But is the design of proteinase inhibitors as drugs a realistic goal, or would other approaches lead to a greater chance of successfully treating arthritis, such as the development of inhibitors of cytokine action ${ }^{108}$

It would obviously be detrimental to totally inactivate an enzyme that had an important physiological role. For instance, one would expect t-plasminogen activator to be such an enzyme, and the matrix metalloproteinases are quite probably important to normal connective tissue remodelling. The primary role of cathepsin B is as a digestive enzyme in lysosomes, ${ }^{109}$ although it may also be important in class II antigen presentation. ${ }^{110}$ However, evidence from gene knockout experiments might suggest that there is a greater redundancy than previously expected in many biological systems. A recent example is that of the plasminogen activators in mice. Inactivation of the $t$-plasminogen activator gene produced a moderate impairment of clot lysis, and that of the uplasminogen activator gene lead to only occasional fibrin deposition. Mice homozygous for the double deletion suffered from extensive fibrin deposition and a slightly shorter lifespan, suggesting that the plasminogen activators could compensate to some degree for each others' absence. ${ }^{111}$ With these double knockout animals one might have expected the resulting phenotype to be more severe. The fact that it was not lends support to the hypothesis that other proteinases are capable of partially fulfilling the function of a plasminogen activator when the need arises. The ability to inhibit totally a proteolytic enzyme may therefore not lead to such drastic consequences as might have been imagined. It is to be hoped that partial suppression of the proteolytic degradation of cartilage will be sufficient to assist in the treatment of arthritis.

More specific proteinase inhibitors are becoming available for laboratory work and these are of great value (as we have described earlier) for the assignation of a pathophysiological function to a particular proteinase. However, there are many problems to be overcome before the descendants of these inhibitors can be used successfully as drugs. To be of practical use in the treatment of joint disease they should be orally active. Most proteinase inhibitors are based on a peptide structure that confers specificity of inhibition. But of course the peptide bond does not survive long in the alimentary canal, rich in proteolytic enzymes. Similarly, acid labile groups would be rapidly destroyed in the stomach, and metabolic instability will result if part of the drug's structure is an enzyme substrate. Knowing the shape and physicochemical properties of a peptide based inhibitor permits further experimentation towards replacing the peptide bonds and other labile components with more stable structures, while retaining the overall properties of the molecule. Presumably small molecule inhibitors will be easily absorbed through the gut. Yet even here the chemical properties of the inhibitor can make an enormous difference to absorption rates. ${ }^{112}$ The compound must then be able to pass through other barriers (connective tissue matrices, cell layers, basement membranes) to become bioavailable at the site of action. And then it must be retained in an active form at this site for a realistic period of time. Perhaps the currently most active area in terms of the development of bioavailable proteinase inhibitors is for the inhibition of the HIV protease as a treatment for AIDS. Progress in this area has been rapid ${ }^{113}$ and suggests that the HIV protease (retropepsin; EC 3.4.23.16) may become second to angiotensin converting enzyme (peptidyl-dipeptidase A; EC 3.4.15.1) (114 $^{11}$ as a protease that is a therapeutic target. Competition is coming from matrix metalloproteinase inhibitors. Inhibitors of matrix metalloproteinases with sufficient oral bioavailability to achieve therapeutic blood concentrations have already entered clinical trials for the treatment of cancer (Drummond A, 86th Annual Meeting of the American Association for Cancer Research, Toronto, 1995). ${ }^{115}$

The question of whether the target enzymes are extracellular or intracellular becomes relevant at this point. There is some evidence to suggest that at least part of the proteolytic pathway of cartilage breakdown is intracellular. In some respects it is easier to target an intracellular protein. If a drug is capable of entering the target cell, it is then much less likely to be lost from the system. It is also possible to use "prodrugs" that are metabolically inactive until they have entered the cell and been modified by some intracellular enzyme. CA074 methyl ester is such a compound, being inactive as a cathepsin B inhibitor until it has been deesterified. ${ }^{32}$ Cathepsin $B$ is a lysosomal enzyme and lysosomes are rich in esterase activity. Upon de-esterification, the compound regains its carboxyl group and is therefore no longer membrane permeant. This approach allows for the enrichment of the drug at the site of action while preventing non-specific effects that the active form might have outside the cell.

The ability to inhibit the pathological breakdown of cartilage without affecting normal physiological turnover would be beneficial. The observation that cathepsin B appears to be involved in IL-1, but not retinoate, stimulated proteoglycan breakdown suggests the existence of two converging cascades, ${ }^{35}$ and opens up the possibility of differential inhibition of aggrecan, and possibly collagen, breakdown. 
On the other hand, in order for an inhibitor of cartilage breakdown to be effective it may prove necessary to target the proteinases directly responsible for cartilage matrix proteolysis. In the case of type II collagen breakdown this is most likely to be interstitial collagenase, about which a great deal is already known and for which inhibitors have already been developed. The question as to the identity of the enzyme proximal to aggrecan breakdown remains open, and this will be an area of intensive research over the next few years.

\section{Markers of cartilage degradation}

New inhibitors of specific proteinases are becoming available for clinical evaluation in the treatment of osteoarthritis or rheumatoid arthritis. It is therefore essential that there should be a good biochemical method of measuring the clinical efficacy of these drugs as cartilage protecting agents. Changes in levels of joint pain, swelling and stiffness, assessed on clinical examination, do not necessarily reflect an inhibition of cartilage degradation. Inhibition of joint-space narrowing as judged by $x$ ray would not be feasible because it would take too long for any changes to become apparent by so insensitive a technique. Cartilage changes could be assessed by magnetic resonance imaging (MRI) ${ }^{116}$ although the technique has not yet been perfected for this purpose and may be too specialised for routine use. MRI may provide a good clinical standard against which new biochemical markers can be tested.

Some biochemical markers of aggrecan degradation are already available, although they have not yet been fully characterised. For example, Poole et $a l^{117}$ have made antibodies directed against keratan sulfate and chondroitin sulfate epitopes on aggrecan and used them to study proteoglycan molecules in the serum and joint fluid of patients with osteoarthritis and rheumatoid arthritis. The keratan sulfate epitope is thought to be present in both degraded and newly synthesised aggrecan molecules, whereas the chondroitin sulfate epitope is mainly found in the newly synthesised pool of aggrecan and not on the degraded fragments. The authors claimed therefore that their assays for keratan sulfate and chondroitin sulfate could be used to estimate aggrecan degradation and synthesis, respectively. A more accurate measure of aggrecan degradation may come from the use of antibodies directed against the aggrecanase cleavage site neoepitope, ${ }^{118}$ as this epitope, unlike keratan sulfate, would not be detected on the intact molecule and so would be more specific. The carboxy terminal propeptide of type II collagen (CPII; chondrocalcin) ${ }^{119}$ can be detected in joint fluid ${ }^{120}$ and is regarded as a marker of type II collagen synthesis. Its concentrations in joint fluid are higher in osteoarthritis than in rheumatoid arthritis. Type I collagen crosslinks provide a good marker of bone collagen degradation. ${ }^{121}$ They can be detected in both urine and serum and are thought to offer a promising new approach to the monitoring of patients with metabolic bone disease. There are currently no good serum or joint fluid markers of type II collagen degradation. Even in arthritis, circulating concentrations of degraded type II collagen $\alpha$-chains are probably very low and the type II collagen cross-links are not specific for cartilage collagens. In order to quantify the products of type II collagen degradation, it will be necessary to identify and characterise the circulating fragments so that specific assays can be developed for them rather than for random regions of the denatured $\alpha$ chains.

The authors are supported by a grant from the Arthritis and Rheumatism Council (UK).

1 Hollander AP, Atkins RM, Eastwood DM, Dieppe PA Elson CJ. Human cartilage is degraded by rheumatoid arthritis synovial fluid but not by recombinant cytokines in vitro. Clin Exp Immunol 1991;83:52-7.

2 Hollander AP, Heathfield TF, Webber C, Iwata Y, Bourne $\mathrm{R}$, Rorabeck $\mathrm{C}$, et al. Increased damage to type II collagen in osteoarthritic articular cartilage detected by a new in osteoarthritic articular cartilage detected

3 Venn M, Maroudas A. Chemical composition and swelling of normal and osteoarthritic femoral head cartilage. Ann Rheum Dis 1977;36:121-9.

4 Dodge GR, Poole AR. Immunohistochemical detection and immunochemical analysis of type II collagen degradation in human normal, rheumatoid, and osteoarthritic articular cartilages and in explants of bovine articular cartilage cultured with interleukin-1. $\mathcal{F}$ Clin Invest 1989;83:647-61.

5 Dodge GR, Pidoux I, Poole AR. The degradation of type II collagen in rheumatoid arthritis: an immunoelectron microscopic study. Matrix 1991;11:330-8.

6 Lohmander LS, Neame PJ, Sandy JD. The structure of aggrecan fragments in human synovial fluid. Arthritis Rheum 1993;36:1214-22.

7 Kempson G. The mechanical properties of articular cartilage. In: Sokoloff $\mathrm{L}$, ed. The joints and synovial fluid. Vo 2. New York: Academic Press, 1980:177-238.

8 Nomenclature Committee of the IUBMB. Enzyme nomenclature. London: Academic Press, 1992:371-2.

9 Barrett AJ, Saklatvala J. Proteinases in joint disease. In: Kelley WN, Harris ED, Ruddy S, Sledge CB, eds. Text book of rheumatology. Philadelphia: WB Saunders, 1985:

10 Fell HB, Mellanby E. The effect of hypervitaminosis A on embryonic limb-bones cultivated in vitro. $\mathcal{F}$ Physiol (Lond) 1952;116:320-49.

11 Lucy JA, Dingle JT, Fell HB. Studies on the mode of action of excess of vitamin A. 2. A possible role of intracellular proteases in the degradation of cartilage matrix. Biochem $f$ 1961;79:500-8.

12 Dingle JT. Studies on the mode of action of excess of vitamin A. 3. Release of a bound protease by the action of vitamin A. Biochem f 1961;79:509-12.

13 Fell HB, Dingle JT. Studies on the mode of action of excess of vitamin A. 6. Lysosomal protease and the degradation of cartilage matrix. Biochem ₹ 1963;87:403-8.

14 Wu Y, Gadina M, Tao-Cheng J-H, Youle RJ. Retinoic acid disrupts the Golgi apparatus and increases the cytosolic routing of $743-53$.

15 Lohnes D, Dierich A, Ghyselinck N, Kastner P, Lampron $\mathrm{C}$, LeMeur $\mathrm{M}$, et al. Retinoid receptors and binding proteins. F Cell Sci 1992;Suppl 16:69-76.

16 Saklatvala J, Pilsworth LMC, Sarsfield SJ, Gavrilovic J, Heath JK. Pig catabolin is a form of interleukin 1. Cartilage and bone resorb, fibroblasts make prostaglandin and collane and thymocyte proliferation is augmented in response to one protein. Biochem $\mathcal{f} 1984 ; 224: 461-6$.

17 Saklatvala J. Tumour necrosis factor $\alpha$ stimulates resorption and inhibits synthesis of proteoglycan in cartilage. Nature 1986;322:547-9.

18 Fontana A, Hengartner H, Weber E, Fehr K, Grob PJ, Cohen $G$. Interleukin 1 activity in the synovial fluid of patients with rheumatoid arthritis. Rheumatol Int 1982;2: $49-53$.

19 DiGiovine FS, Manson J, Nuki G, Duff GW. Tumour necrosis factor activity in synovial exudate fluids from patients with RA and OA. Br $\mathcal{F}$ Rheumatol 1986;25:108.

20 Pettipher ER, Higgs GA, Henderson B. Interleukin 1 induces leukocyte infiltration and cartilage proteoglycan
degradation in the synovial joint. Proc Natl Acad Sci USA 1986;83:8749-53.

21 Leong WS, Russell RGG, Caswell AM. Stimulation of cartilage resorption by extracellular ATP acting at P2-
purinoceptors. Biochim Biophys Acta 1994;1201:298-304.

22 Xie D, Homandberg GA. Fibronectin fragments bind to and penetrate cartilage tissue resulting in proteinase expression and cartilage damage. Biochim Biophys Acta pression and cartilage

23 Thomas L. Reversible collapse of rabbit ears after intravenous papain, and prevention of recovery by cortisone. F Exp Med 1956;104:245-52. 
24 Rawlings ND, Barrett AJ. Evolutionary families of peptidases. Biochem f 1993;290:205-18.

25 Ali SY. The degradation of cartilage matrix by an intracellular protease. Biochem $\mathcal{7}$ 1964;93:611-17.

26 Ali SY, Evans L, Stainthorpe E, Lack CH. Characterization of cathepsins in cartilage. Biochem $\mathcal{f}$ 1967;105:549-57.

27 Van Noorden CJF, Vogels IMC, Everts V, Beertsen W. Localization of cathepsin B activity in fibroblasts and chondrocytes by continuous monitoring of the formation of a final fluorescent reaction product using 5-nitrosalicylaldehyde. Histochem $\mathcal{F}$ 1987;19:483-7.

28 Baici A, Lang A. Effect of interleukin- $1 \beta$ on the production of cathepsin B by rabbit articular chondrocytes. FEBS Lett 1990;277:93-6.

29 Dessau W, Sasse J, Timpl R, Jilek F, von der Mark K. Synthesis and extracellular deposition of fibronectin in chondrocyte cultures. Response to the removal of extracellular cartilage matrix. F Cell Biol 1978;79:342-55.

30 Van Noorden CJF, Smith RE, Rasnick D. Cysteine proteinase activity in arthritic rat knee joints and the effect of a selective systemic inhibitor, Z-Phe- $\mathrm{AlaCH}_{2} \mathrm{~F}$. $f$ Rheumatol 1988;15:1525-35.

31 Brömme D, Steinert A, Friebe S, Fittkau S, Wiederander $B$, Kirschke $\mathrm{H}$. The specificity of bovine cathepsin S. Biochem F 1989;264:475-81.

32 Buttle DJ, Murata M, Knight CG, Barrett AJ. CA074 methyl ester: a proinhibitor for intracellular cathepsin B. Arch Biochem Biophys 1992;299:377-80.

33 Buttle DJ, Saklatvala J, Tamai M, Barrett AJ. Inhibition of interleukin 1-stimulated cartilage proteoglycan deof interleukin 1-stimulated cartilage proteoglycan degradation by a lipophilic inactivator of

34 Buttle DJ, Saklatvala J. Lysosomal cysteine endopeptidases mediate interleukin 1-stimulated cartilage proteoglycan degradation. Biochem $\mathcal{F}$ 1992;287:657-6

35 Buttle DJ, Handley CJ, Ilic MZ, Saklatvala J, Murata M, Barrett AJ. Inhibition of cartilage proteoglycan release by a specific inactivator of cathepsin B and an inhibitor of matrix metalloproteinases. Evidence for two converging pathways of chondrocyte-mediated proteoglycan degradation. Arthritis Rheum 1993;36:1709-17.

36 Yocum SA, Lopresti-Morrow LL, Gabel CA, Milici AJ Mitchell PG. Bafilomycin Al inhibits IL-1-stimulated proteoglycan degradation by chondrocytes without affecting stromelysin synthesis. Arch Biochem Biophys 1995;316:827-35.

37 Lovejoy B, Cleasby A, Hassell AM, Longley K, Luthe $M A$, Weigl D, et al. Structure of the catalytic domain of fibroblast collagenase complexed with an inhibitor. Science 1994;263:375-7.

38 Reinemer P, Grams F, Huber R, Kleine T, Schnierer S, Piper M, et al. Structural implications for the role of the N-terminus in the "superactivation" of collagenases. A
crystallographic study. FEBS Lett 1994;338:227-33.

39 Bode W, Gomis-Rüth F-X, Stöckler W. Astacins, serra lysins, snake venom and matrix metalloproteinases exhibit identical zinc-binding environments (HEXXHXXGXXH and Met-turn) and topologies and should be grouped into a common family, the "metzincins". FEBS Lett 1993; 331: $134-40$.

40 Murphy G, Reynolds JJ. Extracellular matrix degradation. In: Royce P, Steinmann B, eds. Connective tissue and it heritable disorders. New York: Wiley-Liss, 1993:287-316.

41 Murphy GJP, Murphy G, Reynolds JJ. The origin of matrix Lett 1991;289:4 -7.

42 Dayer JM, Breard J, Chess L, Krane SM. Participation of monocyte-macrophages and lymphocytes in the production of a factor that stimulates collagenase and prostaduction of a factor that stimulates collagenase and prostaglandin release by

43 Murphy G, Hembry RM, Reynolds JJ. Characterization of a specific antiserum to rabbit stromelysin and demonstration of the synthesis of collagenase and stromelysin by stimulated rabbit articular chondrocytes. Collagen Relat Res 1986;6:351-64.

44 Brinckerhoff CE. Joint destruction in arthritis: metalloproteinases in the spotlight. Arthritis Rheum 1991;34: 1073-5.

45 Andrews HJ, Plumpton TA, Harper GP, Cawston TE. A synthetic peptide metalloproteinase inhibitor, but not Timp, prevents the breakdown of proteoglycan within Timp, prevents the breakdown of proteoglycan within

46 Nixon JS, Bottomley KMK, Broadhurst MJ, Brown PA, Johnson WH, Lawton G, et al. Potent collagenase inhibitors prevent interleukin 1-induced cartilage degradation in vitro. Int $\mathcal{F}$ Tissue React 1991;13:237-43.

47 Caputo CB, Sygowski LA, Wolanin DJ, Patton SP, Caccese $\mathrm{RG}$, Shaw A, et al. Effect of synthetic metalloprotease inhibitors on cartilage autolysis in vitro. $\mathcal{F}$ Pharmacol Exp Ther 1987;240:460-5.

48 Liotta LA, Goldfarb RH, Brundage R, Siegal GP, Terranova V, Grabisa S. Effect of plasminogen activator (urokinase), plasmin, and thrombin on glycoprotein and collagenous components of basement membrane Cancer Res 1981;41:4629-36.

49 Werb Z, Mainardi CL, Vater C, Harris ED. Endogenous activation of latent collagenase by rheumatoid synovial cells. $N$ Engl f Med 1977;296:1017-23.

50 Mayer $M$. Biochemical and biological aspects of the plasminogen activation system. Clin Biochem 1990;23:197 211.

51 Riccio A, Grimaldi G, Verde P, Sebastio G, Boast S, Blasi F. The human urokinase-plasminogen activator gene and its promoter. Nucleic Acids Res 1985;13:2759-71.
52 Degen SJF, Rajput B, Reich E. The human tissue plasminogen activator gene. f Biol Chem 1986;261:6972-85.

3 Lijnen HR, Van Hoef B, Nelles L, Collen D. Plasminogen activation with single-chain urokinase type plasminogen activation with single-chain urokinase type plasm

54 Hoyalerts M, Rijken DC, Lijnen HR, Collen D. Kinetics of the activation of plasminogen by human tissue plasminogen activator. F Biol Chem 1982;257:2912-19.

55 Blasi F, Stoppelli MP, Cubellis MV. The receptor for urokinase-plasminogen activator. $\mathcal{F}$ Cell Biochem 1986;32: 179-86.

56 Blasi F. Surface receptors for u-PA. Fibrinolysis 1988;2 73-84

57 Dingle JT, Dingle TT. The site of cartilage matrix degradation. Biochem f 1980;190:431-8.

58 Bunning RAD, Crawford A, Richardson HJ, Opdenakker G, Van Damme J, Russell RGG. Interleukin 1 preferentially stimulates the production of tissue-type plasentially stimulates the production of tissue-type plasminogen activator by human articula
Biochim Biophys Acta 1987;924:473-82.

59 Liezer T, Claris BJ, Ash PE, Van Damme J, Saklatvala J, Hamilton J. Interleukin- $1 \beta$ and interleukin- $1 \alpha$ stimulate the plasminogen activator activity and prostaglandin $\mathrm{E}_{2}$ levels of human synovial cells. Arthritis Rheum 1987;30 562-6.

60 Campbell IK, Piccolli DS, Roberts MJ, Muirden KD, Hamilton JA. Effects of tumour necrosis factor $\alpha$ and $\beta$ on resorption of human articular cartilage and production of plasminogen activator by human articular chondrocytes. Arthritis Rheum 1990;33:542-52.

61 Meats JE, Elford PR, Bunning RAD, Russell RGG. Retinoids and synovial factor(s) stimulate the production of plasminogen activator by cultured human chondrocytes. plasminogen activator by cultured human chondrocytes. A possible role for plasminogen activator in the resorption $161-9$

62 Buttle DJ. Lysosomal cysteine endopeptidases in the degradation of cartilage and bone. In: Dingle JT, Davies ME, eds. Textbook of immunopharmacology. Immunopharmacology of joints and connective tissue. London: Academic Press, 1994:225-43.

63 Mimuro J, Schleef R, Loskutoff DJ. Extracellular matrix of cultured bovine aortic endothelial cells contains functionally active type 1 plasminogen activator inhibitor. Blood 1987;70:721-8.

64 Knusden BS, Harpel PC, Nachman RL. Plasminogen activator inhibitor is associated with the extracellula matrix of cultured bovine smooth muscle cells. $f$ Clin Invest 1987;80:1082-9.

65 Collier S, Ghosh P. The role of plasminogen in interleukin1 mediated cartilage degradation. F Rheumatol 1988;15: 1129-37.

66 Oweida SW, Ku DN, Lumsden AB, Kam CM, Powers JC. In vivo determination of the anticoagulant effect of a substituted isocoumarin (ACITIC). Thromb Res 1990; 58:191-7.

67 Martel-Pelletier J, Faure MP, McCollum R, Mineau F, Cloutier JM, Pelletier JP. Plasmin, plasminogen activators and inhibitor in human osteoarthritic cartilage. $\mathcal{F}$ Rheum atol 1991;18:1863-971.

68 Mochan E, Uhl U. Elevations in synovial fluid plasminogen activator in patients with rheumatoid arthritis. $\mathcal{F}$ Rheum atol 1984;11:123-8.

69 Kikuchi H, Tanaka S, Matsuo O. Plasminogen activator in synovial fluid from patients with rheumatoid arthritis. f Rheumatol 1988;15:1138-43.

70 Belch JJF, McArdle B, Madhok R, McLaughlin K, Capell HA, Forbes CD, et al. Decreased plasma fibrinolysis in patients with rheumatoid arthritis. Ann Rheum Dis 1984; 43:774-7.

71 Ayad S, Boot-Handford R, Humphries MJ, Kadler K, Shuttleworth A. The extracellular matrix facts book. London: Academic Press, 1994:18.

72 Sandy JD, Flannery CR, Neame PJ, Lohmander LS. The structure of aggrecan fragments in human synovial fluid. f Clin Invest 1992;89:1512-16.

73 Ilic MZ, Handley CJ, Robinson HC, Mok MT. Mechanism of catabolism of aggrecan by articular cartilage. Arch Biochem Biophys 1992;294:115-22.

74 Sandy JD, Neame PJ, Boynton RE, Flannery CR Catabolism of aggrecan in cartilage explants. F Biol Chem bolism of aggrecan

75 Loulakis P, Shrikhande A, Davis G, Maniglia C. N-termina sequence of proteoglycan fragments isolated from medium of interleukin-1-treated articular-cartilage cultures. Biochem fै 1992;284:589-93.

76 Fosang AJ, Neame PJ, Hardingham TE, Murphy G, Hamilton JA. Cleavage of cartilage proteoglycan between $\mathrm{G}$ and $\mathrm{G} 2$ domains by stromelysin. $\mathcal{F}$ Biol Chem 1991;266: 15579-82.

77 Fosang AJ, Neame PJ, Last K, Hardingham TE, Murphy G, Hamilton JA. The interglobular domain of cartilage aggrecan is cleaved by PUMP, gelatinases and cathepsin B. F Biol Chem 1992;267:19470-4.

78 Flannery CR, Lark MW, Sandy JD. Identification of stromelysin cleavage site within the interglobular domain of human agrecan. 7 Biol Chem 1992;267:1008-14.

79 Fosang AJ, Last K, Neame PJ, Murphy G, Knäuper V, Tschesche $\mathrm{H}$, et al. Neutrophil collagenase (MMP8) Tschesche $\mathrm{H}$, et al. Neutrophil collagenase (MMP8) cleaves at the aggrecanase site E373-A374 in the in
terglobular domain of cartilage aggrecan. Biochem $\mathcal{F} 1994$; 304:347-51

80 Nguyen Q, Liu J, Roughley PJ, Mort JS. Link protein as a monitor in situ of endogenous proteolysis in adult human articular cartilage. Biochem $\mathcal{f}$ 1991;278:143-7. 
81 Nguyen Q, Murphy G, Hughes CE, Mort JS, Roughley PJ. Matrix metalloproteinases cleave at two distinct sites on human cartilage link protein. Biochem $f$ 1993;295: on human 8 .

82 Cheah KSE, Stoker NG, Griffin JR, Grosveld FG, Solomon E. Identification and characterization of the human type II collagen gene (COL2A1). Proc Natl Acad Sci USA 1985;82:2555-9.

83 Bornstein P, Ehrlich HP, Wyke AW. Procollagen: conversion of the precursor to collagen by a neutral protease. Science 1972;175:544-6.

84 Mitchell N, Shepard N. Changes in proteoglycan and collagen in rheumatoid arthritis. F Bone foint Surg 1978; 60A:349-54.

85 Kobayashi I, Ziff M. Electron microscopic studies of the cartilage-pannus junction in rheumatoid arthritis. Arthcartilage-pannus junction in
ritis Rheum 1975;18:475-83.

86 Gross J, Nagai Y. Specific degradation of the collagen molecule by tadpole collagenolytic enzyme. Proc Natl Acad Sci USA 1965;54:1197-204.

87 Gross J, Highberger JH, Johnson-Wint B, Biswas D. Mode of action and regulation of tissue collagenase. In: Woolley DE, Evanson JM, eds. Collagenase in normal and pathological connective tissues. Chichester: Wiley, 1980:11-35.

88 Burleigh MC, Barrett AJ, Lazarus GS. Cathepsin B1: a lysosomal enzyme that degrades native collagen. Biochem lysosomal enzyme that

89 Barrett AJ. The possible role of neutrophil proteinases in damage to articular cartilage. Agents Actions 1978;8: $15-18$.

90 Wu J-J, Lark MW, Chun LE, Eyre DR. Sites of stromelysin cleavage in collagen types II, IX, X and XI. $\mathcal{f}$ Biol Chem 1991;266:5625-8.

91 Page AE, Fuller K, Chambers TJ, Warburton MJ. Purification and characterization of a tripeptidyl peptidase I from human osteoclastomas: evidence for its role in bone resorption. Arch Biochem Biophys 1993;306:354-9.

92 Murphy G, Ward R, Gavrilovic J, Atkinson S. Physiological mechanisms for metalloproteinase activation. Matrix 1992;Suppl 1:224-30.

93 Murphy G, Cockett MI, Stephens PE, Smith BJ, Docherty AJP. Stromelysin is an activator of procollagenase. A study with natural and recombinant enzymes. Biochem $\mathcal{F}$ 1987;248:265-8.

94 Ellis AJ, Curry VA, Powell EK, Cawston TE. The prevention of collagen breakdown in bovine nasal cartilage by TIMP, TIMP-2 and a low molecular weight synthetic inhibitor Biochem Biophys Res Commun 1994;201:94-101.

95 Hughes CE, Caterson B, White RJ, Roughley PJ, Mort JS Monoclonal antibodies recognizing protease-generated neoepitopes from cartilage proteoglycan degradation. $\mathcal{f}$ neoepitopes from cartilage pro
Biol Chem 1992;267:16011-14.

96 Kobayashi H, Schmitt M, Goretzki L, Chucholowski N, Calvete J, Kramer M, et al. Cathepsin B efficiently activates the soluble and the tumor cell receptor-bound form of the proenzyme urokinase-type plasminogen activator (pro-uPA). F Biol Chem 1991;266:5147-52.

97 Eeckhout Y, Vaes G. Further studies on the activation of procollagenase, the latent precursor of bone collagenase. Effects of lysosomal cathepsin B, plasmin and kallikrein, and spontaneous activation. Biochem $₹$ 1977;166:21-31.

98 Rowan AD, Mason P, Mach L, Mort JS. Rat procathepsin B. Proteolytic processing to the mature form in vitro. $\mathcal{F}$ B. Proteolytic processing to the
Biol Chem 1992;267:15993-9.

99 Dalet-Fumeron V, Guinec N, Pagano M. In vitro activation of pro-cathepsin B by three serine proteinases: leucocyte elastase, cathepsin $G$, and the urokinase-type plasminogen activator. FEBS Lett 1993;332:251-4.

100 Sato H, Takino T, Okada Y, Cao J, Shinagawa A, Yamamoto E, et al. A matrix metalloproteinase expressed on the surface of invasive tumour cells. Nature 1994;370: $61-5$.

101 Lafyatis R, Kim S-J, Angel P, Roberts AB, Sporn MB, Karin $M$, et al. Interleukin-1 stimulates and all-transretinoic acid inhibits collagenase gene expression through its $5^{\prime}$ activator protein-1-binding site. Mol Endocrinol $1990 ; 4: 973-80$.

102 Brinckerhoff CE, Harris ED. Modulation by retinoic acid and corticosteroids of collagenase production by rabbit synovial fibroblasts treated with phorbol myristate acetate or poly(ethylene glycol). Biochim Biophys Acta 1981;677: 424-32.

103 Bauer EA, Seltzer JL, Eisen AZ. Retinoic acid inhibition of collagenase and gelatinase expression in human skin fibroblast cultures. Evidence for a dual mechanism. $\mathcal{f}$ Invest Dermatol 1983;81:162-9.

104 Wolf $\mathrm{G}$. The molecular basis of the inhibition of collagenase by vitamin A. Nutr Rev 1992;50:292-4.

105 Connolly TJ, Clohisy JC, Shilt JS, Bergman KD, Partridge NC, Quinn CO. Retinoic acid stimulates interstitial colNC, Quinn CO. Retinoic acid stimulates interstitial collagenase messenger ribonucleic acid

106 Birktoft JJ, Breddam K. Glutamyl endopeptidases. Methods Enzymol 1994;244:114-26.

107 Dingle JT. Cartilage maintenance in osteoarthritis: interaction of cytokines, NSAID and prostaglandins in articular cartilage damage and repair. $\mathcal{F}$ Rheumatol 1991; 18:30-7.

108 Elliott MJ, Maini RN, Feldmann M, Long-Fox A, Charles $\mathrm{P}$, Katsikis $\mathrm{P}$, et al. Treatment of rheumatoid arthritis with chimeric monoclonal antibodies to tumor necrosis wactor $\alpha$. Arthritis Rheum 1993;12:1681-90.

109 Barrett AJ, Buttle DJ, Mason RW. Lysosomal cysteine proteinases. ISI Atlas of Science: Biochemistry 1988;1: 256-60.

110 Matsunaga Y, Saibara T, Kido H, Katunuma N. Participation of cathepsin B in processing of antigen presentation to MHC class II. FEBS Lett 1993;324:325-30.

111 Carmeliet P, Schoonjans L, Kieckens L, Ream B, Degen $\mathrm{J}$, Bronson R, et al. Physiological consequences of loss of plasminogen activator gene function in mice. Nature 1994; 368:419-24.

112 Tamai M, Matsumoto K, Omura S, Koyama I, Ozawa Y, Hanada $K$. In vitro and in vivo inhibition of cysteine proteinases by EST, a new analog of E-64. $₹$ Pharproteinases by EST, a new
macobiodyn 1986;9:672-7.

113 Abdel-Meguid SS, Metcalf BW, Carr TJ, Demarsh P, Des Jarlais RL, Fisher S, et al. An orally bioavailable HIV-1 protease inhibitor containing an imidazole-derived peptide bond replacement: crystallographic and pharmacokinetic analysis. Biochemistry 1994;33:11671-7.

114 Rich DH. Peptidase inhibitors. In: Sammes PG, ed. Comprehensive medicinal chemistry. Vol 2. Oxford: Pergamon, 1990:391-441.

115 Cawston T. Blocking cartilage destruction with metalloproteinase inhibitors: a valid therapeutic target? $A n n$ loproteinase inhibitors: a vald
Rheum Dis 1993;52:769-70.

116 Recht MP, Resnick D. MR imaging of articular cartilage: current status and future directions. Am $\mathcal{F}$ Roentgenol 1994;163:283-90.

117 Poole AR, Ionescu M, Swan A, Dieppe PA. Changes in cartilage metabolism in arthritis are reflected by altered serum and synovial fluid levels of the cartilage proteoglycan aggrecan. $f$ Clin Invest 1994;94:25-33.

118 Hughes CE, Caterson B, Fosang AJ, Roughley PJ, Mort JS. Monoclonal antibodies that specifically recognize neoepitope sequences generated by "aggrecanase" and matrix metalloproteinase cleavage of aggrecan: application to catabolism in situ and in vitro. Biochem $f$ 1995;305: 799-804.

119 Choi HU, Tang L-H, Johnson TL, Pal S, Rosenberg LC, Reiner A, et al. Isolation and characterization of a 35,000 molecular weight subunit fetal cartilage matrix protein. $\mathcal{F}$ Biol Chem 1983;258:655-61.

120 Shinmei M, Ito K, Matsuyama S, Yoshihara Y, Matsuzawa $\mathrm{K}$. Joint fluid carboxy-terminal type II procollagen peptide as a marker of cartilage collagen biosynthesis. Osteoarthritis and Cartilage 1993;1:121-8.

121 Demers LM, Kleerekoper M. Recent advances in biochemical markers of bone turnover. Clin Chem 1994;40: 1994-5. 